\title{
Decoração aumentada: utilizando Design Thinking para detectar oportunidades no uso da realidade aumentada na compra de móveis online Augmented decoration: using Design Thinking to detect opportunities in the use of augmented reality in purchase of furniture online
}

\author{
Guto Kawakami \& Wilson Prata.
}

realidade aumentada, design thinking, compra de móveis.

Com o investimento das empresas na utilização da realidade aumentada, novas oportunidades surgiram no mercado. Nesta pesquisa, é realizada uma investigação para entender como essa tecnologia pode ser aplicada no processo de compra de móveis online. Para conduzir este estudo foi utilizada a metodologia Design Thinking.

augmented reality, design thinking, purchase of furniture.

With business investment in the use of augmented reality, new opportunities have emerged in the market. In this research, an investigation is carried out to understand how this technology can be applied in the purchase of furniture online. To conduct this study was used the methodology Design Thinking.

\section{Introdução}

Com o avanço da tecnologia novas oportunidades de interação têm surgido. Essas interações possibilitam novas práticas, que por conseguinte, mudam a forma como agimos e pensamos as tarefas do cotidiano. Neste contexto, a realidade aumentada (RA) tem tido um papel importante, pois é uma interface computacional avançada, que ainda não foi implantada de forma expressiva na sociedade (Kirner \& Siscoutto, 2007).

Atualmente, várias empresas têm lançado novos produtos utilizando a RA, grande parte deles são em forma de aplicativos, websites e serviços web. Segundo Ferreira et al. (2005, p.2) esses artefatos digitais exercem hoje uma influência decisiva nas atividades e no desenvolvimento humano. Diante disso, atividades como pagar contas bancárias, comunicação rápida, pedido de transporte, dentre outras, podem ser citadas como tarefas que estão sendo facilitadas por meio dos aplicativos e demais tecnologias.

Uma das atividades que foram facilitadas através dos produtos tecnológicos, foi a compra de produtos online. Agora para comprar algo, o usuário pode abrir uma página web, aplicativo ou serviço onde se encontra o que deseja e efetuar a compra através de um cartão de crédito. Essa prática vem crescendo cada vez mais no Brasil, segundo o levantamento chamado Total Retail da PwC (2016), onde foram entrevistadas mil pessoas, 38,2\% dos brasileiros têm o hábito de fazer compras online todos os meses, contra 30,9\% que declararam comprar em lojas físicas com a mesma frequência. Somente $3,4 \%$ dos consumidores entrevistados nunca adquiriram produtos através de serviços online.

Apesar da constante presença dos aplicativos no cotidiano dos usuários e do crescimento do mercado de smartphones, o computador ainda é o meio preferido no Brasil e no mundo para realizar compras online, $34,4 \%$ dos brasileiros declararam usá-lo para adquirir produtos mensalmente, enquanto $15,8 \%$ fizeram uso de tablets e $15,3 \%$ disseram usar smartphones (PwC, 2016).

Anais do 9 CIDI e 9 CONGIC

Luciane Maria Fadel, Carla Spinillo, Anderson Horta, Cristina Portugal (orgs.)

Sociedade Brasileira de Design da Informação - SBDI

Belo Horizonte | Brasil | 2019

ISBN 978-85-212-1728-2
Proceedings of the 9th CIDI and 9th CONGIC

Luciane Maria Fadel, Carla Spinillo, Anderson Horta,

Cristina Portugal (orgs.)

Sociedade Brasileira de Design da Informação - SBDI

Belo Horizonte | Brazil | 2019

ISBN 978-85-212-1728-2 
Dentre as compras realizadas online, um setor de compras que tem crescido bastante seu volume de vendas é o de móveis e objetos de decoração. O jornal digital E-Commerce News afirma que no primeiro semestre de 2014 o comércio digital de casa e decoração no Brasil movimentou quase $R \$ 1$ bilhão.

Porém, mesmo com o crescimento das vendas online ainda existe muita resistência por parte dos consumidores em utilizar o serviço, alguns não se sentem seguros e outros preferem se locomover até a loja física para analisar o móvel ao vivo.

Entendendo que existe essa lacuna, esta pesquisa visa estudar como a RA tem sido utilizada no processo de compra de móveis online. A partir da consolidação dos conhecimentos adquiridos, espera-se compreender o estado da arte do uso da RA quando aplicada neste contexto, assim como detectar outras oportunidades de uso.

Para conduzir essa pesquisa, utilizou-se a abordagem do Design Thinking. Por ser um estudo exploratório, será relatado os achados da primeira e da segunda etapa desse ciclo, no caso, considerando as etapas definidas por Vianna (2012): imersão, ideação e prototipação, esta pesquisa focou apenas em imersão e ideação. A etapa de imersão do Design Thinking foi priorizada devido o fato de seus objetivos estarem diretamente relacionados com o entendimento do problema e por disponibilizarem técnicas suficientes e adequadas para tal.

\section{Referencial Teórico}

\section{Realidade Aumentada}

A realidade aumentada tem sido muito explorada pelas grandes empresas nos dias atuais, de jogos à aplicativos utilitários. Esta tecnologia tem estado em foco no sentido de abrir oportunidades para gerar novos produtos. Segundo Azuma (1997) a Realidade Aumentada é uma variação de Ambientes Virtuais, ou Realidade Virtual (RV) como é popularmente chamada. As Tecnologias de RV deixam o usuário completamente imerso em um ambiente sintético, fazendo com que ele não possa enxergar o mundo real ao seu redor. Já a RA acrescenta objetos virtuais sobrepostos ou compostos com o mundo real. Portanto, entende-se que a RA complementa a realidade em vez de substituí-la. Fernandes e Sánchez (2008) afirmam que em um cenário ideal, o usuário deveria ter a impressão de que os objetos virtuais e reais coexistem no mesmo espaço, sendo muito difícil distinguir o real do virtual. Para facilitar a compreensão deste conceito, a figura 1 mostra um exemplo de uma cena com realidade aumentada:

Figura 1 - Cena com Realidade Aumentada (Aplicativo Lego ARStudio)

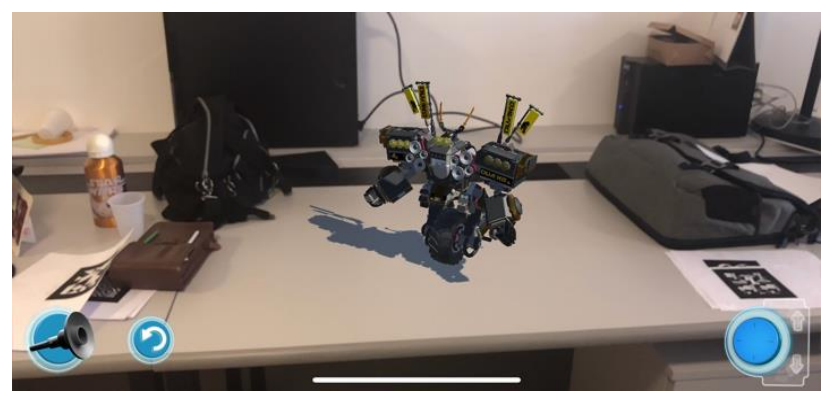

Nesta cena, através da tela de um smartphone, é possível ver o ambiente real com um objeto virtual incluso, no caso o robô.

Outros autores propõem que a RA faz parte de um conceito chamado Realidade Mista. Fernandes e Sánchez (2008) definem Realidade Mista como uma estrutura geral que inclui as transições entre o ambiente real e o ambiente virtual, passando pela realidade aumentada e pela virtualidade aumentada, mas excluindo os extremos. A figura 2 mostra um esquema 
taxionômico estabelecido por Milgram e Kishino (1994) que ajuda a identificar as relações entre os tipos de realidade:

Figura 2 - Taxionomia da relação entre RA e RV

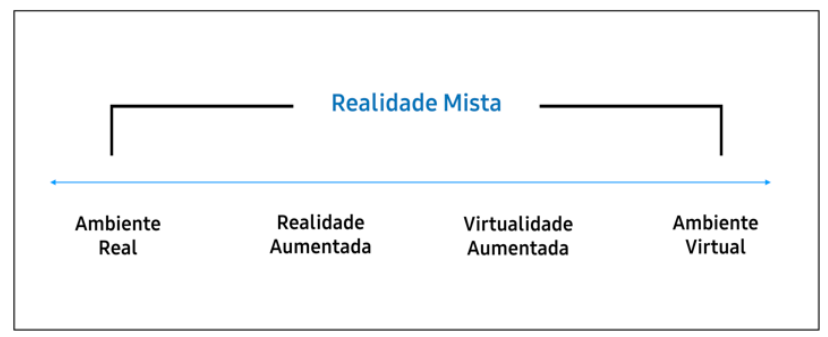

Através deste esquema é possível entender as diferenças entre os conceitos. Nos extremos tem-se de um lado o ambiente real e do outro o ambiente virtual, na transição de ambos está a RA e a virtualidade aumentada, esta ultima que é muito parecida com a realidade aumentada, porém está mais próxima da realidade virtual, na verdade, trata-se da adição de objetos reais em um ambiente virtual (Fernandes \& Sánchez, 2008).

\section{Design Thinking}

Devido a grande concorrência no mercado em um cenário global, inovar tornou-se uma tarefa árdua, pois as dificuldades para conseguir diferenciação entre os concorrentes cresce cada vez mais, sobretudo na área tecnológica. Foi tentando suprir esta lacuna que surgiu o método chamado Design Thinking.

Neste contexto, Brown (2010) diz que o Design Thinking começa com habilidades que os designers têm aprendido ao longo de várias décadas na busca por estabelecer a correspondência entre as necessidades humanas com recursos técnicos disponíveis no mercado. Ao integrar o desejável do ponto de vista humano ao tecnológico e economicamente viável, os designers têm conseguido criar muitos dos produtos que usufruímos hoje. Logo, o Design Thinking representa uma estruturação sistemática desse processo e com isso permite colocar essas ferramentas nas mãos de pessoas e auxilia-las a resolver uma variedade ampla de problemas.

As ferramentas disponibilizadas pelo método estão estruturadas em um modelo de aplicação que segundo Vianna (2012) está dividido em 3 etapas, sendo elas: Imersão, Ideação e Prototipação, como mostra a figura 3:

Figura 3 - Etapas do processo de Design Thinking (Vianna, 2012)

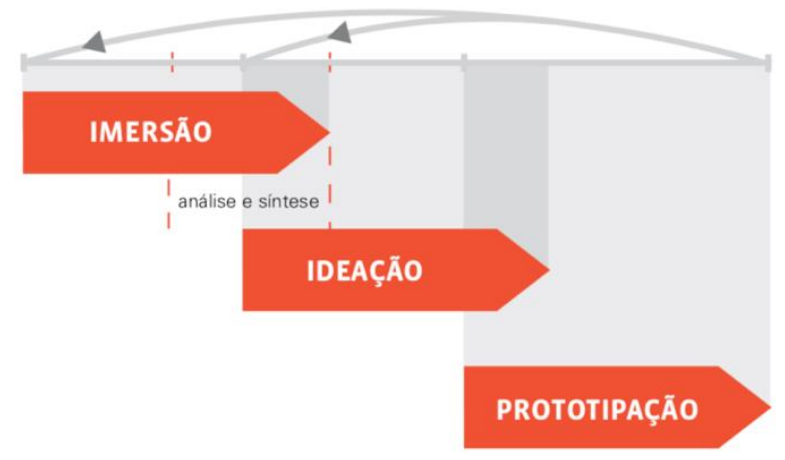

Neste modelo, a primeira etapa é a Imersão e tem como objetivo a aproximação do contexto do projeto. Essa primeira fase é subdividida em duas: Imersão Preliminar e a Imersão em Profundidade. A primeira visa o entendimento inicial do problema, já a outra tem foco em 
identificar oportunidades e necessidades que irão nortear a geração de soluções na próxima fase.

A segunda etapa é a Ideação e busca-se gerar novas ideias através de atividades colaborativas que estimulem a criatividade, nesta etapa as ideias geradas serão selecionadas de acordo com vários critérios, tais como: objetivos de negócio, viabilidade tecnológica, necessidades humanas e etc. E por fim, na etapa de prototipação é realizado o desenvolvimento da ideia selecionada na etapa anterior a fim de prover o aprendizado contínuo e a validação da solução (Vianna, 2012).

Cada etapa do processo fornece um repertório de técnicas para munir os profissionais em suas pesquisas, cada técnica tem suas recomendações, melhores práticas, e o momento certo de usar, ficando a critério do pesquisador escolher qual é a mais adequada dependendo da necessidade.

O Design Thinking é um método que vem sendo utilizado com muita frequência por diversas empresas no mundo todo. Segundo Dorst (2010) nas últimas duas décadas, a metodologia amadureceu consideravelmente ganhando popularidade em vários campos e sendo considerada como um paradigma novo para lidar com problemas em várias áreas como tecnologia da informação, educação, negócios e medicina.

\section{Metodologia}

Para dirigir esta pesquisa utilizou-se a metodologia Design Thinking. A partir deste método, o processo foi estruturado conforme as duas primeiras etapas do método: Imersão e Ideação (Vianna, 2012). A etapa de prototipação não foi realizada neste estudo visto que o objetivo desta pesquisa é entender o estado da arte da RA quando aplicada na compra de móveis online, neste caso as etapas de imersão e ideação forneceram todo o suporte necessário, ficando a prototipagem como um trabalho futuro.

\section{Imersão Preliminar}

Para começar as pesquisas, foi necessário primeiramente ter o entendimento claro do que se trata o problema e seu contexto. Para isso, inicialmente foi feita uma Pesquisa Desk. Vianna (2012) afirma que a Pesquisa Desk é uma busca de informações sobre o tema do projeto em diversas fontes escritas, como: websites, livros, revistas, blogs, artigos, entre outros. Esta técnica foi utilizada para identificar as referências mais relevantes sobre realidade aumentada, entender os principais conceitos da tecnologia e saber o que já existe no mercado no cenário de compras de móveis online. Todas as informações adquiridas através dessa abordagem foram guardadas em um documento para facilitar o acesso as informações. Toda essa pesquisa permitiu compreender melhor as fronteiras e perspectivas do tema em questão.

Em paralelo a Pesquisa Desk, foi realizada a Pesquisa Exploratória. Esta se trata de uma pesquisa de campo que auxilia a equipe no entendimento do contexto a ser trabalhado e fornece insumos para a definição de perfis de usuários (Vianna, 2012). Ao realizar a Pesquisa exploratória, foram entrevistados alguns atores do contexto, como por exemplo: especialistas em realidade aumentada, os considerados "mestres de domínio" e pessoas que costumam comprar móveis online. Essas pessoas forneceram informações relevantes sobre o tema tratado, o que ajudou a enriquecer o repertório de conhecimentos sobre o assunto.

\section{Imersão em Profundidade}

Com o término da imersão preliminar, foi possível obter uma base de informações e referências sobre o tema. Esse estudo forneceu conhecimentos para que fosse possível avançar para a imersão em profundidade, onde o foco está em detectar quais oportunidades e necessidades existem dentro do contexto estudado.

Para adquirir informações que poderão fornecer oportunidades no contexto de compra de móveis online, foi desenvolvido um questionário. Segundo Prata et al. (2012) para desenvolver um questionário, inicialmente deve-se definir as questões de pesquisa, isto é, as questões que 
devem ser esclarecidas pela pesquisa. Estas questões não são as perguntas que estarão presentes para os participantes, pois elas serão desdobradas em perguntas menos intrusivas. Este processo também é importante para definir o modo como serão apresentadas essas questões, como por exemplo: questões abertas, múltipla-escolha, escala de avaliação e etc.

Com base nessas questões de pesquisa um questionário preliminar foi desenvolvido. Ele foi dividido em 4 etapas, sendo a primeira uma tela de apresentação e boas vindas, mostrando qual o objetivo do questionário, assim como a motivação do mesmo. A segunda etapa pretendia saber se o participante costuma comprar online e por qual plataforma costuma comprar. Nesta etapa havia um filtro que direcionava o participante para a etapa 3 ou 4 dependendo de suas respostas. Na terceira etapa foram realizadas perguntas sobre como é o processo de compra de móveis, e por ultimo questões demográficas.

Antes do questionário ser divulgado ao público, foi realizado um teste piloto com alguns participantes de forma presencial. Estes testes tinham como objetivo detectar os pontos de dor no questionário através das reações e respostas dos participantes, assim como obter sugestões que possam contribuir para deixar o questionário melhor elaborado. Ao fim do teste, algumas questões foram reformuladas, outras eliminadas e também houveram questões acrescentadas.

Com as revisões realizadas, o questionário foi aplicado ao público. Os participantes foram convidados a preencher o questionário através de algumas redes sociais (facebook e whatsapp) e do envio de e-mails para instituições de tecnologia. O questionário foi elaborado na plataforma Survey Monkey, e através de seus recursos foi possível: customizar o questionário, disponibilizar o link de acesso aos participantes, assim como guardar as informações obtidas.

Com o término da aplicação do questionário foi obtida informações para a construção do perfil do usuário. Segundo Mayhew (1999), definir o perfil do usuário é a primeira coisa a ser feita para alcançar os objetivos de pesquisa em Interação-Humano-Computador.

O perfil do usuário foi construído após a tabulação e o estudo dos dados. Com base nos resultados, foram identificados três padrões de comportamento, que foram desdobrados em três tipos de perfis: o "cliente regular", o "admirador" e o "especialista". Cada um tem suas particularidades e características que os diferem no processo de compra online. Estes perfis serviram de base para o mapeamento de pessoas que se enquadram em cada perfil. Este mapeamento foi realizado para que fossem escolhidas as pessoas certas a serem entrevistadas.

Após mapear os participantes e enquadra-los no perfil adequado, foram realizadas entrevistas. Fraser (2004) define entrevista como uma conversação dirigida a um propósito definido, no caso desta pesquisa, o propósito é entender o processo de compra online de móveis, detectar pontos de dor, e posteriormente entender como a realidade aumentada pode auxiliar neste processo. No total foram realizadas 4 entrevistas, onde todos os entrevistados tinham o perfil de admirador. O perfil de admirador foi escolhido para o aprofundamento desta pesquisa pois é o perfil que abrange mais pessoas, e também permite entender o cenário dos consumidores finais e não de profissionais da área. Das 4 entrevistas, 3 foram realizadas presencialmente e uma através de vídeo conferência.

A realização das entrevistas permitiu observar os participantes de perto e captar melhor 0 não-dito e os detalhes da comunicação não-verbal. Ao serem abordados sobre o tema, suas expressões, opiniões e reações foram essenciais para mensurar os pontos de dor no processo de compra. Essas informações foram de grande importância para que se entendesse todo o fluxo de atividades e o que eles costumam fazer em cada etapa.

Com esses dados em mãos, o próximo passo dado foi construir uma jornada do usuário. A jornada do usuário é uma representação gráfica das etapas de relacionamento do cliente com um produto ou serviço, que descreve os passos-chave percorridos antes, durante e depois da compra e utilização (Vianna, 2012). Esta técnica foi utilizada para entender o ciclo de atividades dos participantes quando estão realizando o processo de compra. 
O desenvolvimento da jornada foi realizado após a realização das entrevistas e foi estruturado levando em consideração muitos aspectos, como: os sentimentos dos participantes em cada atividade, o tempo que levam para realiza-las, os estágios do processo, dentre outros. Ao mapear essas etapas, foi possível entender as expectativas deles em cada momento, de maneira a criar formas para atendê-los melhor utilizando a RA.

\section{Ideação}

O término da etapa de imersão deixou alguns artefatos a serem utilizados na etapa posterior, como por exemplo: a jornada do usuário. Nesta pesquisa, a fase de ideação consistiu em validar a jornada construída com os entrevistados. Para isso, foi realizado um workshop de validação. O objetivo desse workshop era validar e detalhar a jornada proposta para o perfil de admirador. Este workshop foi realizado entre os pesquisadores e 2 dos entrevistados, cujo o objetivo foi apresentar a jornada do usuário construída e conseguir feedbacks para melhorá-la.

Nesta apresentação todos estavam livres para dar suas opiniões a qualquer momento, logo o workshop também serviu para que todos pudessem pensar e discutir em como a realidade aumentada poderia contribuir no processo de compra de móveis online, assim como detectar os pontos de dor dos participantes neste processo.

O workshop de validação forneceu algumas melhorias que foram incrementadas na jornada do usuário, assim como levantou discussões e forneceu uma construção colaborativa de ideias sobre o uso da RA no processo de compras de móveis. Essas ideias foram documentadas para que em breve elas possam ser utilizadas em uma futura etapa de prototipação.

\section{Resultados}

\section{Análise de Mercado}

Através das pesquisas desk e exploratória foi possível obter várias referências de produtos que já estão no mercado. As pesquisas também permitiram verificar quais funcionalidades que utilizam RA estão sendo usadas nestes produtos. Como resultado desta etapa se obteve uma analise de benchmark em produtos na área do varejo de modo geral, dentre eles podemos citar os aplicativos: Mobly, Coral Visualizer, ShadeScout, Quiver, Bic, Lego X, Amikasa, dentre outros.

Analisando estes produtos, obteve-se uma lista de funcionalidades onde a realidade aumenta é utilizada. Essa listagem está inclusa na tabela 1 e facilitou a compreensão do estado da arte da RA quando aplicada no contexto de compra de produtos online.

Tabela 1 - Funcionalidades da RA

\begin{tabular}{|l|}
\hline Realidade Aumentada - Funcionalidades \\
\hline Renderização de modelos 3D \\
\hline Biblioteca de modelos 3D para projeção \\
\hline Detecção de tags \\
\hline Interação com objetos projetados \\
\hline Mudança de características de objetos projetados \\
\hline Detecção de planos \\
\hline Materialização de desenhos 2D em 3D \\
\hline Mudança nas características do ambiente real \\
\hline
\end{tabular}

Os produtos as quais as funcionalidades foram extraídas também foram colocados em um quadro de comparações. Neste quadro todas as funcionalidades foram analisadas no sentido 
de entender quais são as mais utilizadas no mercado, em quais produtos são mais eficientes e em quais contextos são utilizadas. Os aplicativos foram analisados nos sistemas operacionais iOS e Android, o que permitiu verificar a qualidade das funcionalidades quando usadas através dos frameworks: ARKit, ARCore e Vuforia.

\section{Questionários}

O questionário foi divulgado em redes sociais, como o Facebook e WhatsApp e enviado por email para algumas pessoas que trabalham em institutos de tecnologia. Os resultados adquiridos contemplam apenas o mercado brasileiro, no total houveram 69 participantes (29 homens, 23 mulheres e 7 pessoas não responderam quanto ao seu gênero).

Quanto ao estado civil, 34 pessoas são solteiras, 18 casadas e 7 não responderam. E em relação a quantidade de pessoas que moram juntas, a maioria (20 pessoas) mora com apenas mais uma pessoa, mas não necessariamente são casadas. O questionário obteve as respostas no período de 21 de fevereiro até 24 de fevereiro de 2018 e os participantes estão na faixa etária de 20 a 49 anos.

Estas informações demográficas foram essenciais para a construção dos perfis de usuário. Todos os gráficos foram gerados a partir da ferramenta Survey Monkey e estão mostrados nas figuras abaixo:

Figura 4 -Gênero

Gênero

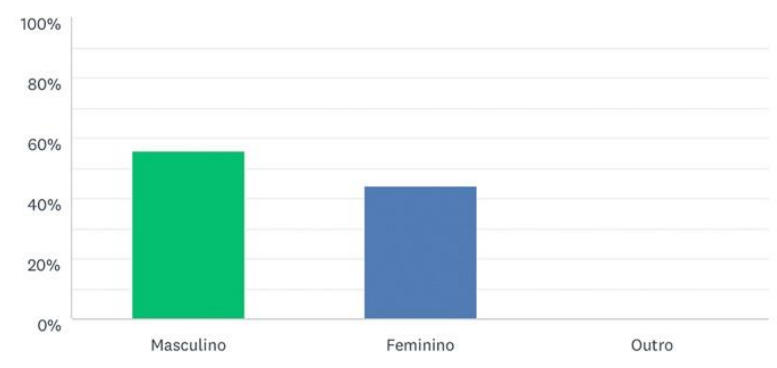

Figura 5 - Estado civil

Estado Civil

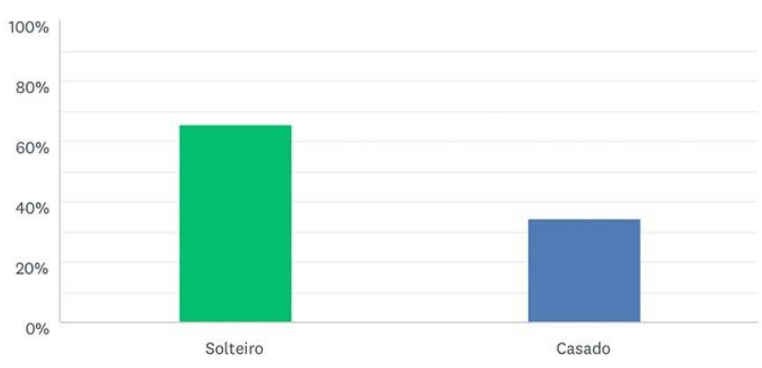


Figura 6 - Moradia

Mora com quantas pessoas?

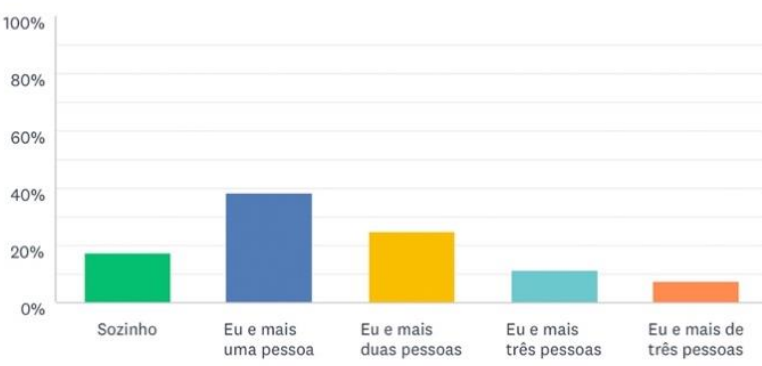

Quando perguntados sobre o que costumam fazer no processo de compra online, as respostas dos participantes ficaram bem niveladas entre buscar preço, informação, alternativas, realizar compras e acompanhar o pedido. Das pessoas que já compraram móveis online estão 29 , contra 14 que nunca utilizaram serviços online para a compra de móveis (16 pessoas não responderam essa questão).

Outro ponto interessante, é saber que o fator determinante da maioria para a compra de móveis é a necessidade. Este fator ocorre devido a diversos contextos, como por exemplo: 0 participante mudou-se para outra cidade e precisa de móveis para sua casa.

Em relação a plataforma de compra, houve empate técnico entre comprar em lojas físicas e no desktop com 27 e 28 respostas respectivamente, nos smartphones houveram apenas 8 respostas e 1 em tablet. Outra informação importante é sobre a busca de informações sobre móveis, onde a maioria dos participantes (34) afirmaram realizar pesquisas online.

Figura 7 - Costume

O que você costuma fazer quando está comprando online?

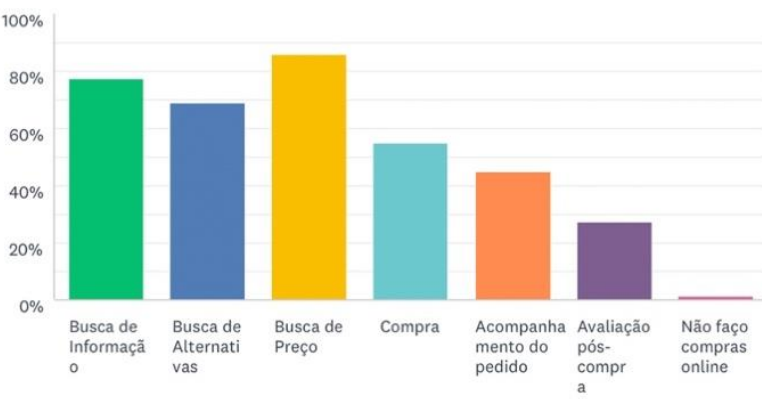

Figura 8 - Compras

Você já comprou móveis para sua casa?

Por exemplo: tapete, cama, sofá.

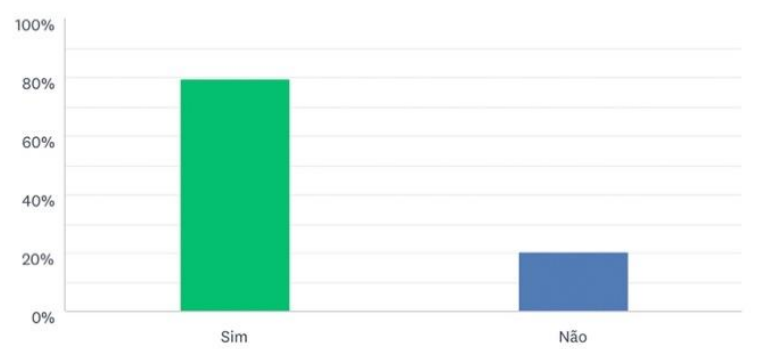

Anais do 9o Congresso Internacional de Design da Informação | CIDI 2019 
Figura 9 - Compras online

Você já comprou móveis online?

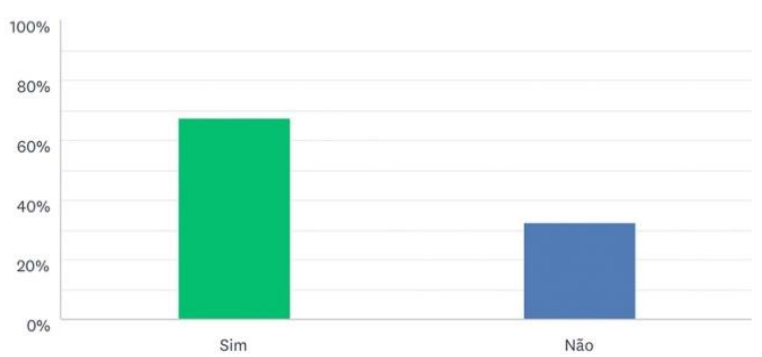

Figura 10 - Escolha

Em uma escala de 1 a 5 , sendo 1 o mais importante e 5 o menos importante, o que lhe faz escolher um móvel?

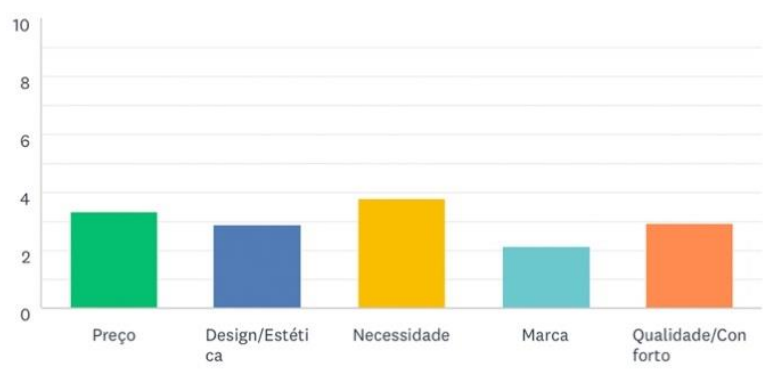

Figura 11 - Situação

Em qual situação você compra um móvel para sua casa?

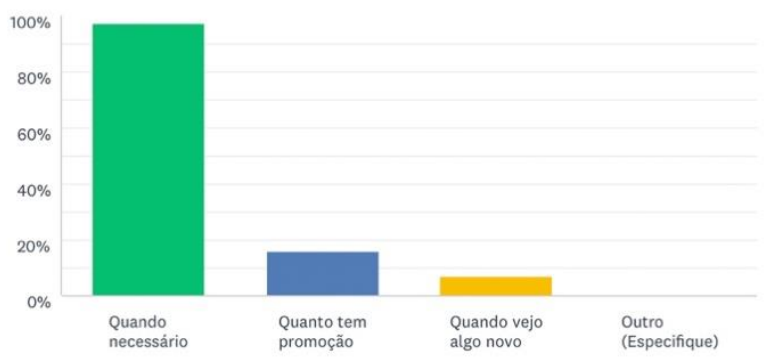


Figura 12 - Busca de informações

Onde você procura informações a respeito de móveis?

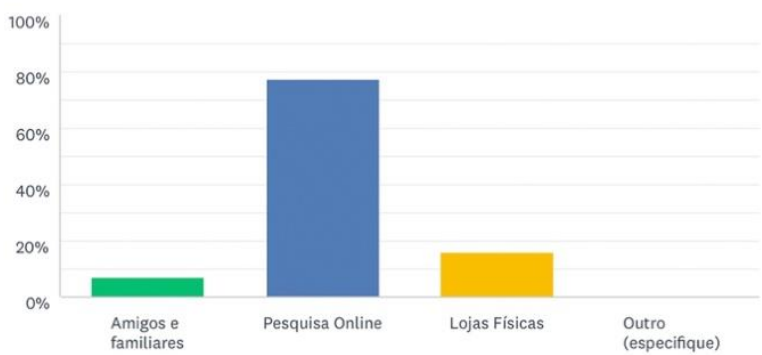

Figura 13 - Plataforma

Onde você costuma comprar móveis?

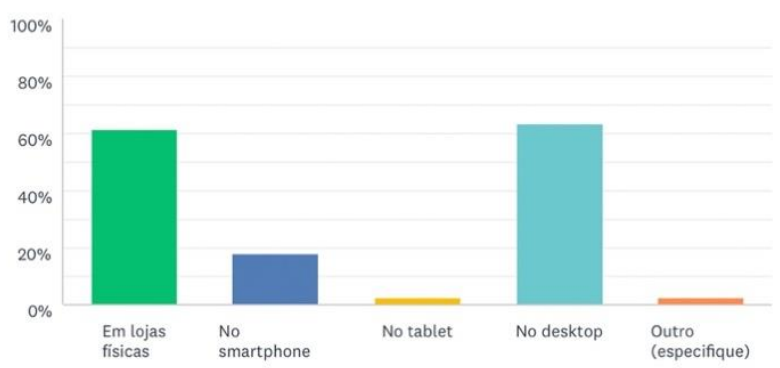

Ao perguntar aos participantes se já enfrentaram alguma dificuldade na compra de um móvel online, obteve-se as seguintes justificativas: 8 pessoas afirmaram enfrentar dificuldades com as dimensões do produto e saber suas características como: cor, material, dentre outros, 7 participantes relataram ter enfrentado problemas com a demora de entrega, 7 pessoas disseram nunca ter tido problemas, e os demais dispersaram-se em relatar problemas como frete, baixa qualidade de móveis ao chegar na residência, processo burocrático e falta de informações para montagem.

Figura 14 - Dificuldades de compra

Você já enfrentou dificuldades na compra de móveis online?
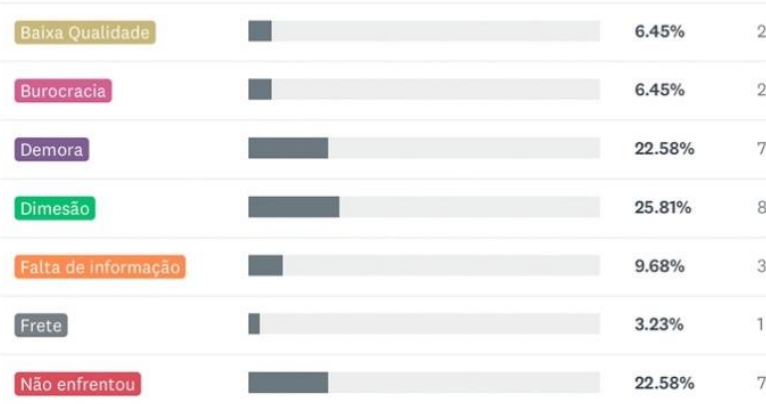

Ao serem questionados sobre qual a parte mais chata na compra de um móvel, os participantes responderam da seguinte forma: 13 pessoas disseram ter dificuldades na escolha dos móveis devido as diversas opções que o mercado oferece, 9 pessoas relataram não saber a dimensão exata do produto, 9 pessoas falaram sobre a demora na entrega e o restante responderam sobre preços altos e baixa qualidade do móvel ao chegar na residência.

Anais do 9 Congresso Internacional de Design da Informação | CIDI 2019

Anais do $9^{\circ}$ Congresso Nacional de Iniciação Científica em Design da Informação | CONGIC 2019

Proceedings of the $9^{\text {th }}$ Information Design Student Conference 
Figura 15 - Parte chata na compra

Qual a parte mais chata na compra de móveis online?

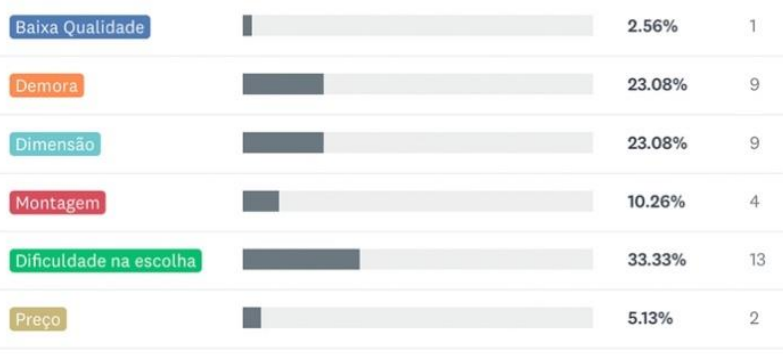

\section{Perfil e Jornada do Usuário}

As respostas do questionário forneceram dados que foram tabulados e estudados, e a partir destes estudos foram desenvolvidos 3 perfis:

(A) Comprador Regular - compra apenas quando necessário, normalmente tem dificuldades em encontrar produtos na internet devido o fato de não entender muito sobre seus materiais, cores e dimensões.

(B) Admirador - pessoas que exigem um bom acabamento nos produtos, são ativos no processo de compra e normalmente gostam de desenvolver os projetos arquitetônicos do ambiente de suas casas.

(C) Especialista - costuma fazer muitas pesquisas na internet antes de comprar o produto. São perfeccionistas em seu trabalho e gostam de coisas novas.

Após o desenvolvimento dos perfis de usuário, foram mapeadas 4 pessoas para serem entrevistadas. Estas pessoas foram enquadradas dentro do perfil do admirador e foram entrevistadas. Destas entrevistas foram obtidos dados para a construção da jornada do usuário, como: pontos de dor, detalhamento das etapas do processo de compra online de móveis e os sentimentos dos participantes em cada etapa.

Esta jornada foi validada no workshop de validação realizado, na qual gerou algumas mudanças que foram incrementadas. Após a validação, obteve-se a seguinte jornada:

(1) Reconhecimento da necessidade: a família se mudou para uma nova casa sem móveis.

(2) Procura de informações: o usuário irá obter a medida dos ambientes; visitar lojas físicas; realizar pesquisas online; consultar amigos especialistas.

(3) Projetar opções: o usuário lista alguns sites e referências que foram pesquisadas.

(4) Conversar com a família/amigos: o usuário compartilha as informações adquiridas para conseguir opiniões.

(5) Avaliar as alternativas: o usuário avalia as alternativas através dos feedbacks obtidos na etapa anterior.

(6) Decidir qual móvel vai comprar: o usuário define a opção de compra, após avaliação.

(7) Compra/envio: o usuário realiza a compra; espera o móvel chegar em sua residência.

(8) Chegada e montagem do móvel: o usuário realiza a montagem do móvel; ou chama um especialista para fazer a montagem.

(9) Uso do móvel: o usuário testa o produto; analisa-o junto do ambiente.

(10) Avalia a compra: o usuário conversa com a família sobre o custo $\mathrm{x}$ benefício.

Anais do 9 Congresso Internacional de Design da Informação | CIDI 2019

Proceedings of the 9th Information Design International Conference 
(11) Realiza manutenções com o tempo: com o passar do tempo o usuário faz manutenções nos móveis para conserva-lo.

O workshop de validação também serviu para detectar oportunidades de uso da realidade aumentada em determinadas fases do processo de compra de móveis online. Elas estão descritas na próxima seção de achados.

\section{Achados: as dores do usuário}

Ao estudar os produtos que já existem no mercado, foi possível entender o estado da arte da utilização da RA no contexto de compra de móveis online. Compreender as principais funcionalidades da tecnologia abre um leque de opções na geração de soluções. Ao analisar os questionários notou-se que muitos participantes relataram não ter a certeza sobre a dimensão dos móveis, material, cor, dentre outras características físicas. A jornada do usuário mostrou outros pontos de dor como a demora na entrega, problemas na montagem de móveis, frete caro e etc. Ao analisar todos esses problemas, um quadro de relacionamento entre realidade aumentada e os pontos de dor dos participantes foi desenvolvido. Neste quadro é descrito os pontos de dores detectados no processo de compra de móveis online e como a RA pode auxiliar através de suas funcionalidades:

Tabela 2 - relação pontos de dor e RA

\begin{tabular}{|c|c|}
\hline Pontos de Dor & \multicolumn{1}{|c|}{ Realidade Aumentada } \\
\hline Demora na entrega & $\begin{array}{l}\text { Não houve sugestões } \\
\text { de uso para auxiliar este } \\
\text { ponto de dor }\end{array}$ \\
\hline Montagem de móveis & $\begin{array}{l}\text { Um manual de } \\
\text { instruções com tags, onde } \\
\text { o comprador pode apontar } \\
\text { a câmera do celular para } \\
\text { ele e o mesmo projeta um } \\
\text { conteúdo explicativo sobre } \\
\text { a montagem do móvel. }\end{array}$ \\
\hline $\begin{array}{c}\text { Dificuldade na } \\
\text { visualização das } \\
\text { características do móvel }\end{array}$ & $\begin{array}{l}\text { A realidade aumentada } \\
\text { poderá projetar o móvel no } \\
\text { ambiente facilitando a } \\
\text { visualização dos materiais, } \\
\text { dimensóes e cores do } \\
\text { produto. }\end{array}$ \\
\hline Frete caro & $\begin{array}{c}\text { Não houve sugestões } \\
\text { de uso para auxiliar este } \\
\text { ponto de dor }\end{array}$ \\
\hline Dificuldades na escolha & $\begin{array}{l}\text { A projeção de móveis } \\
\text { pode auxiliar o usuário na } \\
\text { escolha, podendo o mesmo } \\
\text { vê-lo no ambiente real } \\
\text { antes da compra. }\end{array}$ \\
\hline
\end{tabular}

A tabela 2 mostra algumas sugestões dadas pelos participantes junto dos pesquisadores no workshop de validação. As ideias geradas serão estudadas para que posteriormente possam ser utilizadas em uma etapa de prototipação, concluindo assim o processo do Design Thinking. 


\section{Conclusão}

\section{Considerações Finais}

O presente trabalho de pesquisa, apresentou um estudo sobre a tecnologia da realidade aumentada aplicada dentro do contexto de compra de móveis online. Este estudo foi dirigido através da metodologia Design Thinking, na qual as etapas de imersão e ideação foram utilizadas para adquirir insumos sobre como a RA pode auxiliar no processo de compra de móveis.

A etapa de imersão forneceu uma base teórica sobre os conceitos da realidade aumentada através das técnicas da pesquisa desk e da pesquisa exploratória. A análise de mercado contribuiu para compreender o estado da arte da RA. Todos os produtos analisados serviram para esse entendimento, pois apresentaram as funcionalidades disponíveis até o momento.

A aplicação de questionários auxiliou para detectar os perfis de usuário que compram móveis online, a partir destes perfis foram realizadas entrevistas e adquirido dados para a confecção da jornada do usuário. E por fim, o workshop de validação serviu para validar a jornada construída, entender os pontos de dor e idealizar em que momentos a realidade aumentada pode auxiliar no processo de compra de móveis online.

Portanto, esta pesquisa buscou gerar oportunidades de uso da RA no contexto de compra de móveis online, espera-se que o estudo realizado possa contribuir com os profissionais e estudantes da área na busca de soluções inovadoras para a sociedade.

\section{Perspectivas Futuras}

Este artigo apresentou um estudo adotando a metodologia do Design Thinking, as etapas de imersão e ideação foram utilizadas para que os objetivos desta pesquisa pudessem ser contemplados, contudo, apesar das descobertas obtidas, a última etapa do método denominada prototipação ainda não foi realizada. Como trabalho futuro, pretende-se analisar os insumos adquiridos nas etapas de imersão e ideação e posteriormente amadurecer as ideias geradas, para que estas possam se transformar em protótipos e serem testados pelo público-alvo, e assim contemplar todo o ciclo do Design Thinking.

\section{Agradecimento}

Esta pesquisa foi financiada pela Samsung através de recursos da Lei de Informática.

\section{Referências}

Azuma, R. T. (1997). A survey of augmented reality. Presence: Teleoperators \& Virtual Environments, v. 6, n. 4, p. 355-385.

Brown, T. (2010) Uma metodologia poderosa para decretar o fim das velhas ideias. Design Thinking.

Mayhew, D. J. (1999). The Usability Engineering Lifecycle: apractitionier's handbook for user interface design.

E-Commerce News. (2014). Mulheres são 70\% dos compradores online de móveis, diz pesquisa, consultada em: ecommercenews.com.br/noticias/pesquisasnoticias/mulheres-sao-70-dos-compradores-online-de-moveis-diz-pesquisa.

Fernandes, B. C. A., \& Ssánchez, J. F. (2008). Realidade aumentada aplicada ao design. Holos, v. 1, p. 28-47.

Ferreira, L. F. G., Ramgel, A. C. S., \& Bercht, M. (2005). A educação matemática e a construção do numero pela criança, mediada pela tecnologia digital. RENOTE: revista novas tecnologias na educação [recurso eletrônico]. Porto Alegre, RS. 
Fraser, M. T. D., \& Gondim, S. M. G. (2004). Da fala do outro ao texto negociado: discussões sobre a entrevista na pesquisa qualitativa.

Klirner, R. C. \& Siscoutto, R. (2007). Realidade virtual e aumentada: conceitos, projeto e aplicações. In: Livro do IX Symposium on Virtual and Augmented Reality, Petrópolis (RJ), Porto Alegre: SBC.

Milgram, P. \& Kishino, F. (1994). A taxonomy of mixed reality visual displays. IEICE TRANSACTIONS on Information and Systems, v. 77, n. 12, p. 1321-1329.

Prata, W., Moraes, A., \& Quaresma, M. (2012). User's demography and expectation regarding search, purchase and evaluation in mobile application store. Work, v. 41, n. Supplement 1, p. 1124-1131.

PWC, Total Retail 2016 (2016), consultada em: oglobo.globo.com/economia/brasileiros-jacompram-mais-pela-internet-do-que-em-lojas-fisicas- 18781081 .

Vianna, M. (2012). Design Thinking: inovação em negócios. Design Thinking.

\section{Sobre o(a/s) autor(a/es)}

Guto Kawakami, Sidia, Brasil, <guto.kawakami@sidia.com>

Cinthia Larissa, Sidia, Brasil, <cinthia.costa@sidia.com>

Wilson Prata, Sidia, Brasil, <wilson.prata@sidia.com> 